\title{
Study on the Influence Factors of Rural Landscape in Cold Regions Based on Qualitative Analysis and SPSS Analysis
}

Jie MENG , School of Architecture, Harbin Institute of Technology; Key Laboratory of Cold Region Urban and Rural Human Settlement Environment Science and Technology, Ministry of Industry and Information Technology; East University of Heilongjiang, China.

Qing YUAN, School of Architecture, Harbin Institute of Technology; Key Laboratory of Cold Region Urban and Rural Human Settlement Environment Science and Technology, Ministry of Industry and Information Technology, China. Corresponding Author, E-mail: hityuanqing@hit.edu.cn.

\begin{abstract}
This paper is committed to improving the rural landscape in cold regions. Taking 619 samples of cold rural areas in China as the research object, this paper discusses the influence factors and the relationship of the rural landscape in cold regions. In this paper, the depth structure interview and field survey methods are used to analyze and refine the important influence factors of rural landscape in cold regions. Through the qualitative analysis of NVivo, this paper analyzes the hierarchical relationship of influence factors, and constructs the framework system of influence factors for rural landscape shaping. Then, through questionnaire survey, 619 rural samples are investigated and analyzed for the status of rural landscape impact factors, and the weight of the status quo influence factors is evaluated by SPSS multiple linear regression model. Through the comparative analysis of the results, it is found that exogenous factors play a significant role, endogenous factors lack of power; serious industrial homogenization, high landscape convergence; lack of cultural connotation, weak awareness of protection and inheritance; insufficient use of natural resources, not obvious characteristic climate advantage, and so on. According to the problems, the paper puts forward planning guidance suggestions, in order to make a beneficial contribution to the rural landscape construction in cold regions.
\end{abstract}

\section{Keywords}

rural landscape, cold regions, influence factors, qualitative analysis, SPSS analysis

\section{Introduction}

Rural landscape is the direct embodiment of the rural planning and construction results, and it is the basic premise to explore the rural landscape in the cold region to systematically and objectively explain the elements composition and influence logic of the rural landscape. Rural areas in cold regions have the characteristics of cold climate and low density, and have significant differences and regional characteristics. However, many rural areas have the problems of sameness of landscape, loss of cultural memory, and weak embodiment of industrial characteristics in the aspect of shaping rural landscape in cold regions. It has become an important issue to study the influence logic of rural landscape. At present, international scholars have done a lot of research on the influence factors of rural landscape from the perspectives of natural ecology, industrial economy and policy control. For example, Isabel Martinho (2001) proposed the impact of cultural, economic and technological upgrading on the rural landscape. 
Yao Long (2015) described and classified rural development based on the basic index data of terrain, location, scale, economic industry and other factors through two-step cluster analysis. Pulido Fernandez (2016) demonstrated the coupling relationship between tourism economy and landscape by establishing a binary structure equation. However, in a large number of studies, there is less attention to the rural areas in cold regions, and most of them are limited to the theoretical level and qualitative research, and lack of in-depth investigation and accurate quantitative research from bottom to top. Based on the existing research results, this paper intends to apply qualitative analysis and SPSS quantitative analysis methods to analyze 619 samples of cold rural areas in China. Starting from the basic data of landscape elements, this paper refines the influence factors of rural landscape, and gradually construct the hierarchical factor layer affecting rural landscape, and then explore the formation and development law of rural landscape in cold regions. Through the research, the paper clarifies the endogenous and exogenous influence factors of rural landscape, and provides targeted guidance for improving the overall and characteristic rural landscape in cold regions.

\section{Research design}

\subsection{Research scope}

This paper selects Heilongjiang Province with typical characteristics of cold regions as the research object. Heilongjiang is the province with the northernmost, easternmost, highest latitude and easternmost longitude in China. It is located at $43^{\circ} 26^{\prime} \sim 53^{\circ} 33^{\prime}, 121^{\circ} 11^{\prime} \sim$ $135^{\circ} 05^{\prime}$. It is $1120 \mathrm{~km}$ long from north to south, $930 \mathrm{~km}$ wide from east to west, covering an area of 473000 square kilometers. Heilongjiang is the base of China's heavy industry, with machinery, oil, coal, wood and food industries as the main industries, and it is rich of natural resources, including minerals, forestry, energy, land, animals, plants, water resources, etc. It is the largest grains production base in China. The strategic position is very important. A location map of Heilongjiang is shown in Figure1.

\subsection{Research methods}

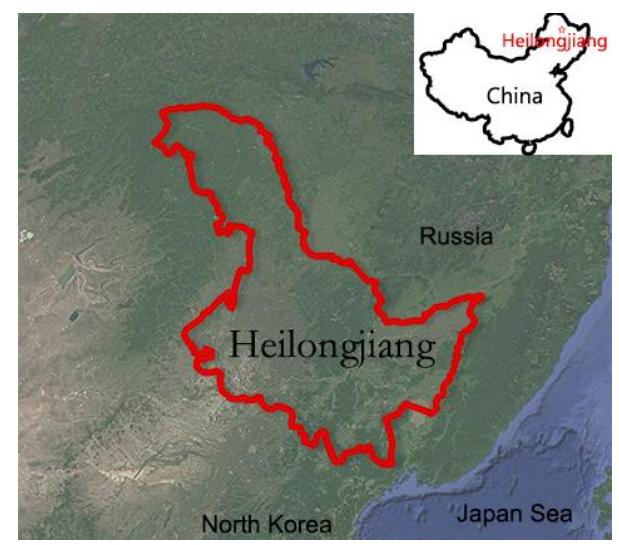

Figure 1. Location of Heilongjiang Province.

Source: drawn by authors.

In this paper, qualitative analysis and SPSS quantitative analysis were used to study the influence factors of rural landscape in cold regions.

(1) Qualitative analysis. Under the guidance of the Grounded Theory, based on the field survey data of 619 rural areas in cold regions, including pictures, text, interview audio and video data, this paper was used NVivo software to process the data semantically, classify and code the data, and extract the influence factors of the rural landscape in cold regions.

(2) SPSS multiple linear regression analysis. On the basis of qualitative analysis, this paper was used the multiple linear regression analysis method of SPSS to obtain the correlation degree between the dependent variables and their respective variables, analyzed which variables are the important influence factors of rural features in cold regions, determined the weight of influence factors of rural features in cold regions, and deeply analyzed the mechanism and problems of influence factors. 


\subsection{Data sources}

The data used in this paper came from the field investigation in cold rural areas, villagers' interview, village cadre interview, and the network questionnaire in the past two years, through a variety of bottom-up survey methods, the statistical information of 619 rural samples was obtained, and the data was reliable and authentic.

\section{Research analysis and results}

\subsection{Qualitative analysis based on Grounded Theory}

In this paper, the survey data of 619 villages in cold regions are sorted out by structural interview method. The collected data are divided into pictures, text, video and audio data. Combined with a large number of literatures, NVivo11 is used to record and analyze. The influence factors of rural landscape are divided into two types: exogenous factors and endogenous factors. The exogenous factors include: location and transportation, current construction, policy and system; the endogenous factors include: natural resources, industrial economy and regional culture. Based on the Grounded Theory, this paper analyzes the first-hand survey data and summarizes the original data. Based on the classification of rural landscape influence factors, the 23 sub-tree nodes are classified into six tree nodes according to different types by axis coding, such as "location and transportation", "current construction", "policy and system", "natural resources", "industrial economy" and "regional culture", as shown in Table1.

Table 1. Statistical table of influence factors of rural landscape. Source: drawn by authors.

\begin{tabular}{|c|c|c|c|}
\hline & $\begin{array}{c}\text { Major } \\
\text { Categories }\end{array}$ & $\begin{array}{l}\text { Middle } \\
\text { Categories }\end{array}$ & Specific influence factors \\
\hline \multirow{6}{*}{$\begin{array}{l}\text { Influence factors } \\
\text { of rural } \\
\text { landscape }\end{array}$} & \multirow{3}{*}{$\begin{array}{l}\text { Exogenous } \\
\text { factors }\end{array}$} & $\begin{array}{l}\text { Location and } \\
\text { transportation }\end{array}$ & $\begin{array}{l}\text { Distance between village and town, traffic } \\
\text { convenience }\end{array}$ \\
\hline & & $\begin{array}{c}\text { Current } \\
\text { construction }\end{array}$ & $\begin{array}{l}\text { Rural scale, rural architecture, courtyard space, } \\
\text { street space, public space, landscape greening, } \\
\text { infrastructure }\end{array}$ \\
\hline & & $\begin{array}{l}\text { Policy and } \\
\text { system }\end{array}$ & $\begin{array}{l}\text { Understanding of rural policy, policy promotion } \\
\text { effect }\end{array}$ \\
\hline & \multirow{3}{*}{$\begin{array}{l}\text { Endogenous } \\
\text { factors }\end{array}$} & $\begin{array}{l}\text { Natural } \\
\text { resources }\end{array}$ & $\begin{array}{l}\text { Topographic features, hydrogeology, regional } \\
\text { climate, vegetation elements }\end{array}$ \\
\hline & & $\begin{array}{l}\text { Industrial } \\
\text { economy }\end{array}$ & $\begin{array}{l}\text { Leading industries, economic development } \\
\text { conditions }\end{array}$ \\
\hline & & $\begin{array}{l}\text { Regional } \\
\text { culture }\end{array}$ & $\begin{array}{l}\text { National language, festival customs, religious } \\
\text { beliefs, myths and legends, celebrity deeds, } \\
\text { regional history }\end{array}$ \\
\hline
\end{tabular}

By further combing the relationship between the influence factors of rural landscape in cold regions, the mechanism of "exogenous factors" and "endogenous factors" of influence factors of rural landscape in cold regions is drawn as shown in Figure2. Among them, exogenous factors include: (1) "Location and transportation" factors provide the basic environmental background for the shaping of rural landscape. Affected by the geographical location and traffic convenience, the degree of rural landscape shaping is different; (2) "Current construction" factors provide the basic conditions for the development of rural 
landscape; (3) "Policy and system" factors provide external driving force for the existing rural landscape. Endogenous factors include: (1) The factors of "natural resources", the composition and distribution of natural resources determine the formation of rural landscape; (2) "Industrial economy" factors, such as the types of leading industries and economic conditions, have an inward influence on the scale and economic strength of rural landscape; (3) "Regional culture" factors reflect the connotation and quality of rural landscape and culture, and largely reflect the spiritual and cultural life of villagers.

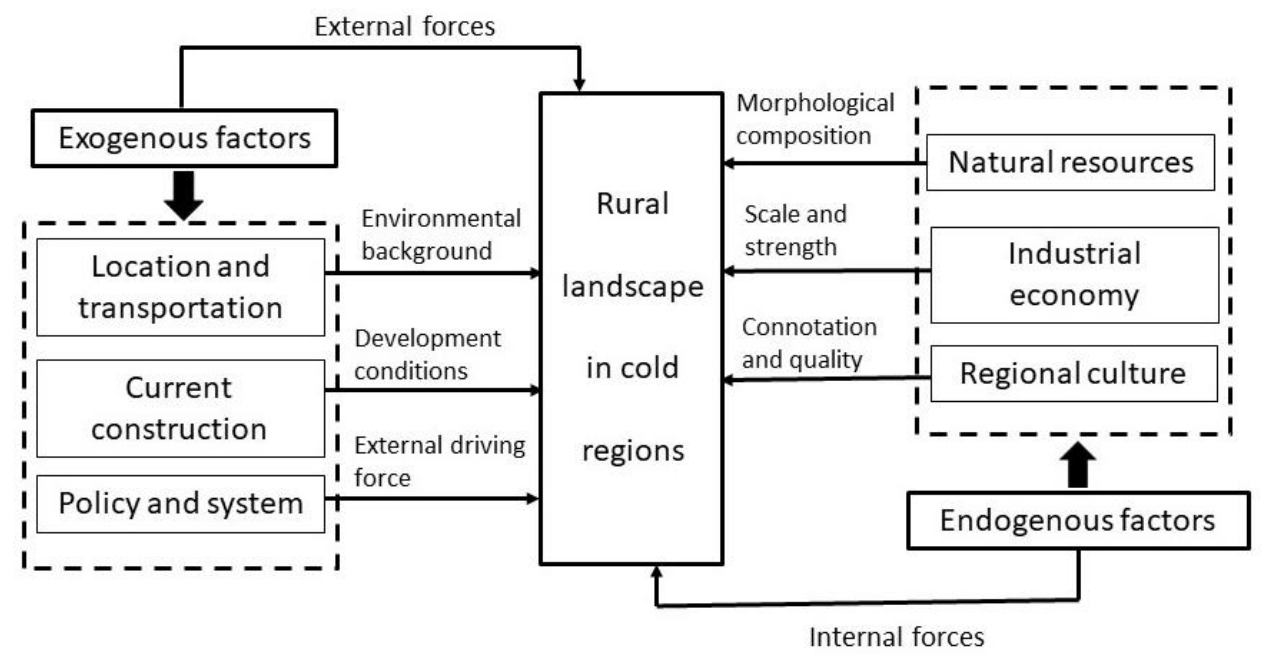

Figure 2. Mechanism of influence factors of rural landscape. Source: drawn by authors.

\subsection{SPSS multivariate regression analysis}

On the basis of qualitative analysis, based on the extracted influence factors, this paper carries out a targeted survey on the development status of the rural landscape influence factors of 619 villages with cold climate characteristics, and evaluates the status quo of influence factors of rural landscape by issuing questionnaires. A total of 637 valid questionnaires were collected from the survey, and the subjects were mainly villagers aged 35-55 who lived in cold rural areas for a long time.

In the questionnaire design, the specific evaluation content includes the following contents: (1)Through the investigation of the distance between village and town, as well as the traffic convenience, it is used to measure the current situation of location and transportation; (2) The contents and villagers' evaluation of current construction as the measurement standard of the current construction; (3) The understanding of policy system and its role in promoting rural landscape are included in the evaluation of rural policy system; (4) The present content of natural resources and the utilization degree of natural resources are regarded as the evaluation contents of natural resources; (5) The structure types of leading industries and the industrial economic situation are used as the criteria for evaluating industrial economy; (6) The elements of regional culture and people's cultural cognition are considered as the evaluation contents of regional culture.

In this paper, the survey results are analyzed by SPSS19.0 software, and the relationship between rural landscape and its influence factors is analyzed by multiple regression analysis. In the study, the "evaluation of the overall rural landscape" is set as the dependent variable, and the results of the sub evaluation of "location and transportation", "current construction", "policy and system", "natural resources", "industrial economy", and "regional culture" are set as independent variables, and then the multiple regression model between variables is constructed. In this paper, through in-depth study of the linear relationship between dependent variables and multiple independent variables, the correlation degree between dependent variables and their respective variables is obtained, which variables are 
important factors affecting the current rural landscape in cold regions is determined, and the weight of influence factors of rural landscape is discussed. The results are as follows:

(1) Overall numerical analysis of the model

The dependent variable "evaluation of the overall rural landscape" and their respective variables "location and transportation", "current construction", "policy system", "natural resources", "industrial economy", and "regional culture" form a multiple linear regression model. The determination coefficient $R^{2}$ of linear fitting regression was 0.806 . It is generally considered that when $\left|R^{2}\right| \geq 0.75$, there is a strong linear relationship between variables.

According to the data in Table 2, the $\mathrm{P}$ (Sig.) value was examined to test the significance among variables. The $P$ value (significance level) of the results was 0.000 . According to the principle of " $P($ Sig. $) \leq 0.05$, the effect of the test is very significant.

Table 2. Model summary data values. Source: drawn by authors.

\begin{tabular}{ccccccc}
\hline Model & $\mathrm{R}$ & $\mathrm{R}^{2}$ & Adjusted $\mathrm{R}^{2}$ & $\begin{array}{c}\text { Error of standard } \\
\text { estimation }\end{array}$ & $\mathrm{F}$ & Sig. \\
1 & $.898^{\mathrm{a}}$ & .806 & .796 & 1.000 & 79.014 & $.000^{\mathrm{a}}$ \\
\hline
\end{tabular}

(2) Analysis of fitting results of multiple linear regression model

According to the results of multiple linear regression equation construction in Table 3, for the dependent variable "evaluation of the overall rural landscape", the independent variables with greater influence are "location and transportation", "natural resources", "current construction" and "policy and system". The significance levels of these four variables are $0.007,0.028,0.000$ and 0.000 , all less than 0.05 , which have a strong impact on the dependent variables. And the significance level of "regional culture" and "industrial economy" are 0.059 and 0.818 respectively, both of which are greater than 0.05 . According to the evaluation of the current situation, the above two variables have little influence on the shaping of rural landscape, and at the same time, it reveals that the inherent development and utilization value of these two factors in rural landscape construction has not been fully exerted, which is worthy of further study.

Table 3. Fitting results of multiple linear regression model (coefficient ${ }^{\mathrm{a}}$ ). Source: drawn by authors.

\begin{tabular}{|c|c|c|c|c|c|}
\hline \multirow{2}{*}{ Model } & \multicolumn{2}{|c|}{$\begin{array}{l}\text { Coefficient of non } \\
\text { standardization }\end{array}$} & \multicolumn{2}{|l|}{$\begin{array}{c}\text { Standard } \\
\text { coefficient }\end{array}$} & \multirow[b]{2}{*}{ Sig. } \\
\hline & B & $\begin{array}{l}\text { Standard } \\
\text { error }\end{array}$ & Beta & $\mathrm{t}$ & \\
\hline (Constant) & .136 & .390 & & .348 & .728 \\
\hline Location and transportation & .142 & .052 & .144 & 2.730 & .007 \\
\hline Current construction & .424 & .074 & .459 & 5.719 & .000 \\
\hline Policy and system & .284 & .075 & .282 & 3.771 & .000 \\
\hline Natural resources & .418 & .188 & .093 & 2.222 & .028 \\
\hline Industrial economy & .019 & .081 & .019 & .230 & .818 \\
\hline Regional culture & .112 & .059 & .117 & 1.906 & .059 \\
\hline
\end{tabular}

a. Dependent variable: evaluation of the overall rural landscape. 
According to the principle of "the greater the Beta value, the greater the impact effect", the ranking results of influence factors of rural landscape are as follows: current construction, policy and system, location and transportation, natural resources, regional culture and industrial economy. Therefore, the weight diagram of influence factors affecting rural landscape is shown in Figure 3. Among them, from the comparison of "exogenous factors" and "endogenous factors", it is found that "exogenous factors" have a greater impact on the shaping of rural landscape, which is shown by the blue bar in Figure 3, while the "endogenous factors" are relatively less prominent, which is shown by the orange column in Figure 3. Among the six medium impact factors, "current construction" has the greatest impact on rural landscape, while "industrial economy" has the least impact.

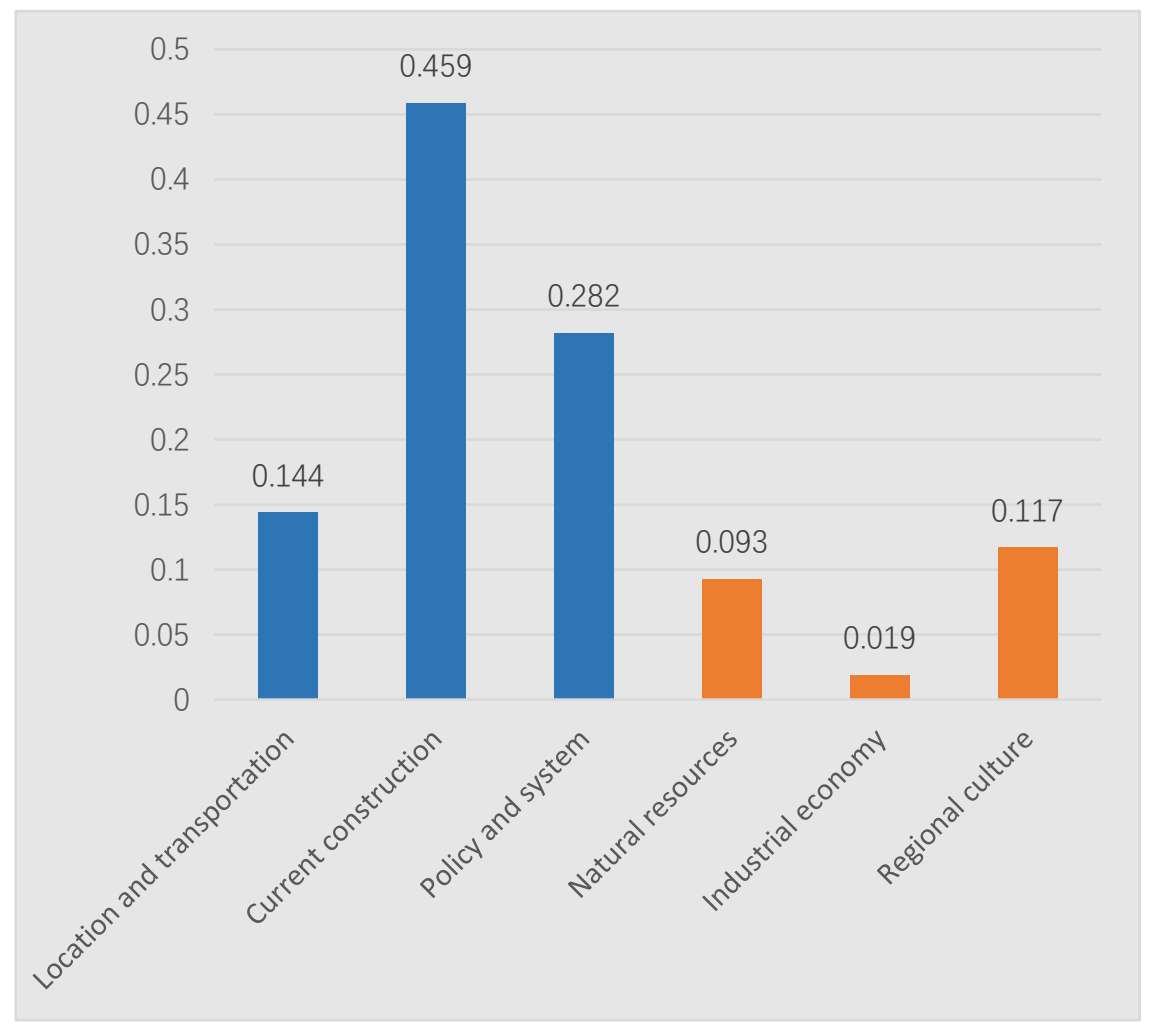

Figure 3. Weight evaluation of influence factors on rural landscape in cold regions. Source: drawn by authors.

\section{Discussions}

\subsection{Exogenous factors play an important role, and endogenous factors are not dynamic} enough

At present, the shaping of rural landscape in cold regions is characterized by significant exogenous factors and insufficient endogenous factors. In the analysis of "exogenous factors", the "current construction" factors specifically include the rural scale, rural buildings, courtyard space, street space, public space, landscape greening, infrastructure and other construction, relatively mature, to a certain extent, which determines the overall situation of the rural landscape. The survey shows that the current construction has the greatest impact on the shaping of the overall rural landscape, and the villagers generally believe that the current construction and the overall rural landscape fit the highest degree. As the basic condition of rural construction, "location and transportation" presents the situation that the closer geographical location is to the town, the higher traffic convenience, and the better overall landscape characteristics. It 
shows the positive effect of "location and transportation" on the shaping of rural landscape. In addition, with the country's attention to rural revitalization, beautiful rural construction has been strongly supported by the government, "policy and system" in the shaping of rural landscape presents an obvious external driving role, which can better implement the rural landscape construction and benefit the people. Compared with the exogenous factors, the endogenous influence power is relatively insufficient. In the analysis of endogenous factors, attention should be paid to the two factors of "industrial economy" and "regional culture", and the root cause of the problem should be found as soon as possible. The specific reasons for the lack of "endogenous factors" are analyzed in detail below.

\subsection{Serious industrial homogeneity, and high landscape similarity}

According to the data survey, the development status of rural "industrial economy" has no obvious effect on the shaping of rural landscape. Tracing the basic situation of rural industrial structure, it is found that $73.55 \%$ of the rural leading industry is the primary industry (agriculture), as shown in Figure 4 . Due to the serious problem of industrial homogeneity, the impact of industry on rural landscape is relatively low. At present, Heilongjiang Province is a typical representative of China's agricultural province and cold regions. Its main crops are rice, corn and soybean. It is rich in forest resources, and has the characteristics of large scale and complete landscape texture, which provides unique conditions for the construction of rural landscape in cold regions. However, it is a serious lack in the current rural landscape that the basic agricultural landscape cannot be fully utilized. At the same time, from the perspective of industrial structure and landscape utilization, it is of great significance to re-examine the overall rural landscape shaping in cold regions. Therefore, according to the current situation, we should appropriately adjust the industrial structure, promote the diversified development of rural industries, and break the shackles of single industrial structure. In addition, we should highlight the important role of industrial landscape, actively shape and make full use of industrial landscape, so as to enhance the overall rural landscape.

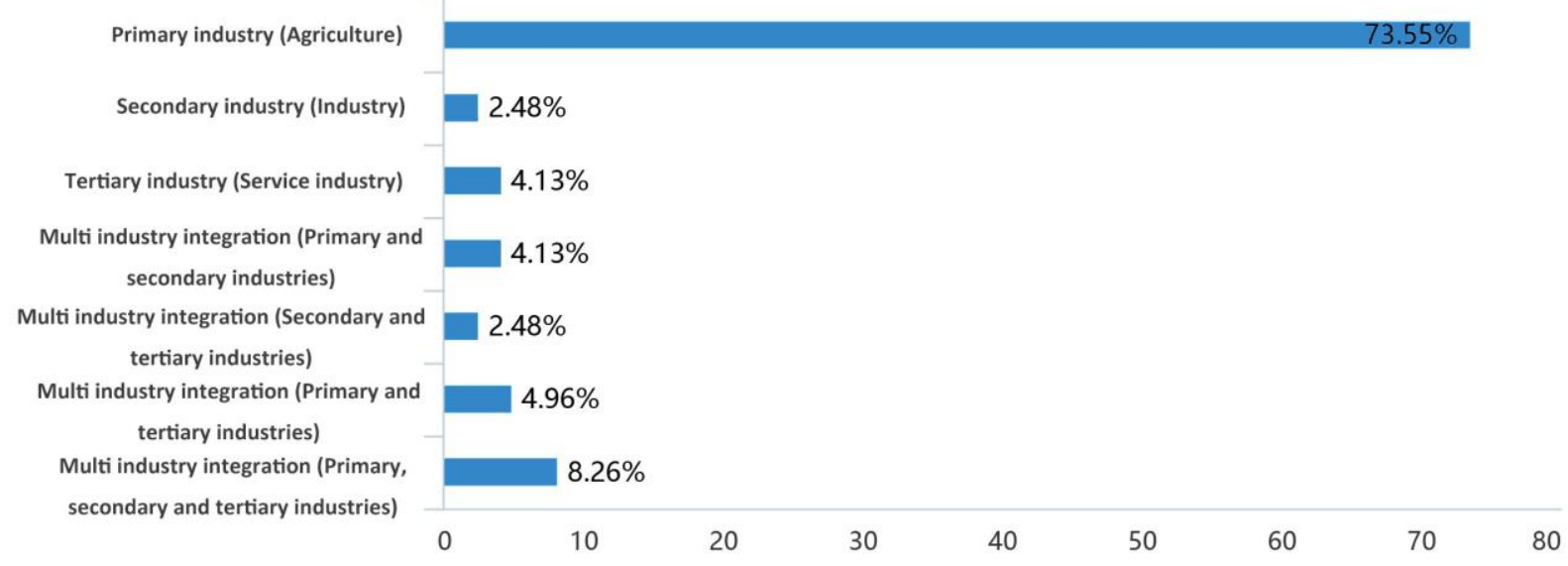

Figure 4. Statistics of rural leading industries. Source: drawn by authors.

\subsection{Lack of cultural connotation, and weak awareness of protection and inheritance}

The significance level of "regional culture" as an independent variable in the multiple regression model is $0.059, \mathrm{P}$ value is close to 0.05 . To a certain extent, it shows that the status quo of regional culture has an impact on rural landscape, but the current significance is not strong enough. At the same time, it exposes the phenomenon that the construction of regional culture is insufficient in the overall shaping of rural landscape, and the lack of cultural connotation. In addition, due to the single industry and relatively backward economy, there is a serious outflow of young people in cold rural areas. Many people go out to work and lack a sense of belonging to their hometown. Due to the lack of rural regional culture, to a large 
extent, the state emphasizes the creation of "nostalgia" in the rural development policy, which also promotes the construction of rural regional culture.

This survey shows that the current shaping of regional culture, regional history, daily cultural training activities in the cultural shaping show better. Festival customs, characteristic folk activities, national language, religious beliefs, myths and legends, celebrity deeds and other contents need to be further shaped in the future, as shown in Figure 5.

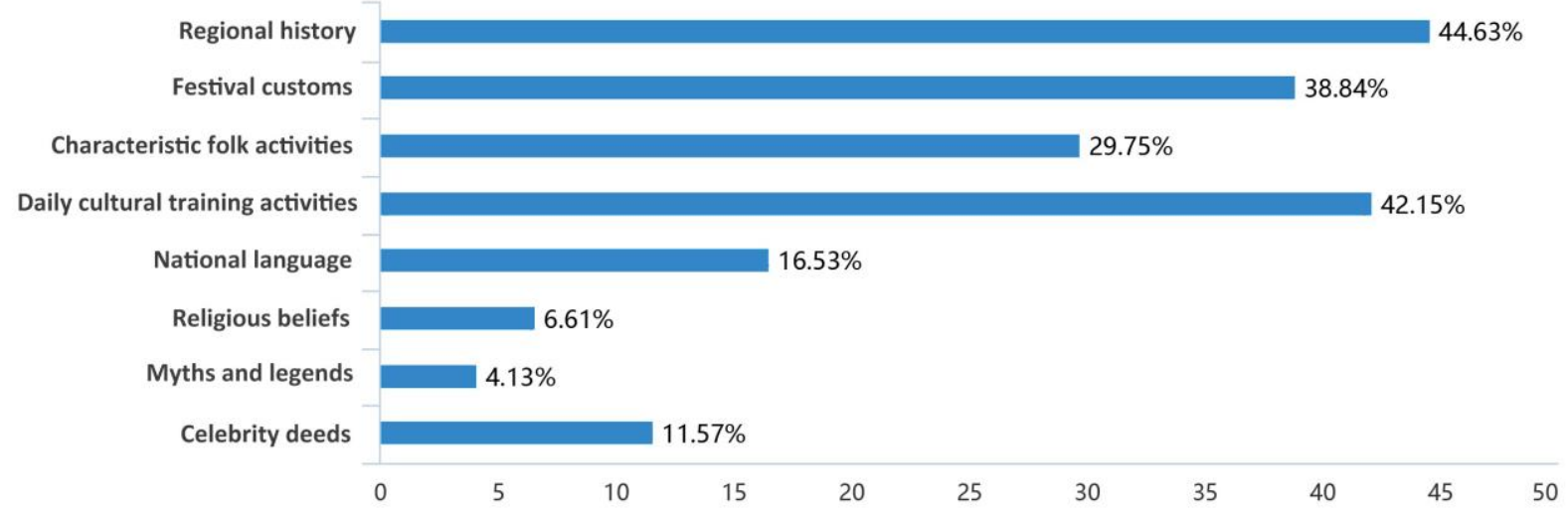

Figure 5. Statistics of regional culture. Source: drawn by authors.

\subsection{Utilization of natural resources is insufficient, and advantage of characteristic climate}

\section{is not obvious}

In the survey of influence factors, it has obvious influence on the shaping of rural landscape, but the third from the bottom index of significance is "natural resources", and its influence significance level is 0.028 . The analysis of rural natural resources in Heilongjiang Province has the following characteristics: As a representative of cold regions, Heilongjiang Province is rich in natural resources, with a large area of farmland, mountains, water, forest, grassland and mineral resources, with unique natural landscape. The survey results are shown in Figure 6. For example, Daxinganling area has 81700 square kilometers of natural forest resources, which provides unique conditions for the development of rural tourism. In addition, the special regional climate conditions provide the resources that can be used. The climate environment of 40-50 degrees below zero in winter can shape the characteristic winter landscape and provide favorable natural conditions for rural characteristic tourism in winter. For example, in the northernmost part of China, Mohe Arctic village makes full use of cold climate conditions, forest resources, original ecological lifestyle, and is supplemented by the characteristic "Aurora Borealis" landscape. Rural tourism is in full swing and is loved by the majority of tourists. However, there are a few villages that can make full use of these natural resources. Many villages in cold regions have good natural conditions, but they are not fully utilized. They are only limited to agricultural production activities. There are problems of insufficient utilization of natural resources in the shaping of rural landscape. At the same time, the phenomenon of convergence of rural landscape and low happiness index of local residents are caused. 


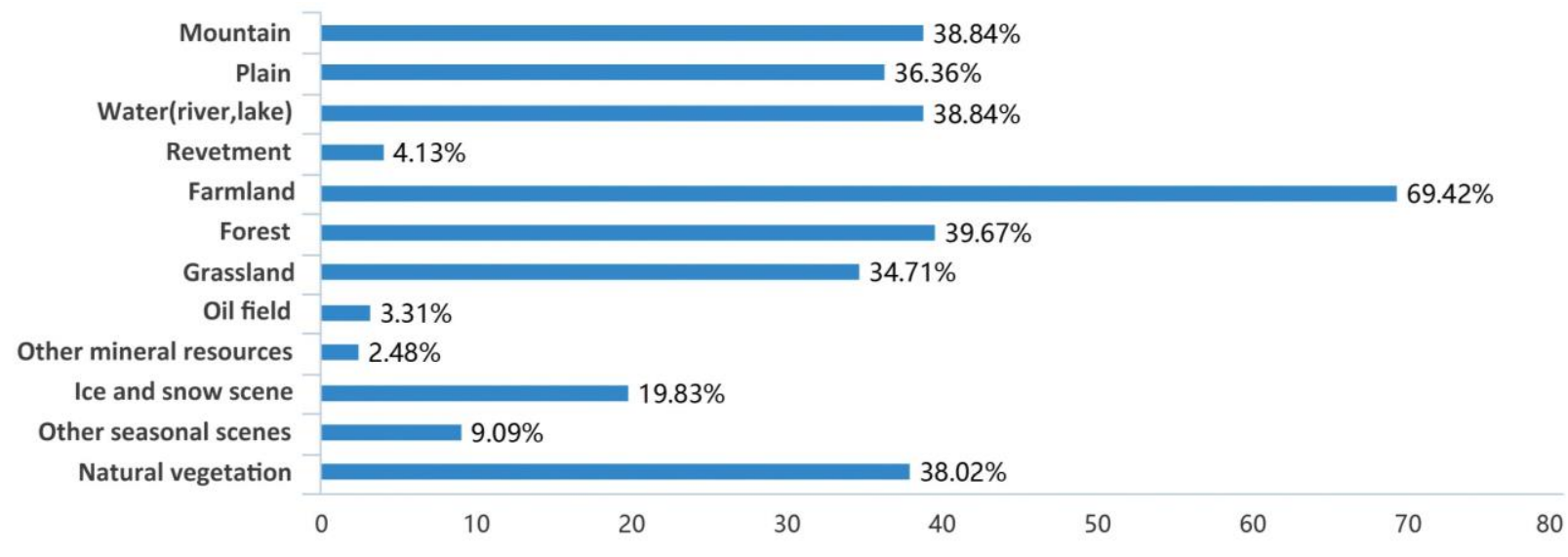

Figure 6. Statistics of natural resources. Source: drawn by authors.

\section{Conclusions}

Through qualitative analysis and SPSS quantitative analysis of 619 rural samples in cold regions, the following conclusions are drawn:

(1) At present, the influence factors of rural landscape are significantly affected by exogenous factors, and the endogenous factors are insufficient. We need to strengthen the role of endogenous factors, focus on the structural adjustment of "industrial economy", the full excavation of "regional culture", and the positive utilization of "natural resources". In particular, we should focus on the regional characteristics of cold rural areas, so as to enhance the overall rural landscape in cold regions.

(2) Through quantitative analysis and ranking the weight of the rural landscape influence factors in cold regions, this paper exposed the serious problem of industrial homogenization, and proposed to break the shackles of single industry through multiple industrial development measures. In addition, this paper suggests that we can study the rural landscape based on the characteristics of different industries, so as to effectively guide the shaping of rural landscape.

(3) The construction of rural cultural connotation, as a non-material form of landscape content, which is often ignored in the shaping of rural landscape. Through research, it has been proved that in rural landscape planning and construction, cultural connotation shaping is as important as material space planning, and it can also highlight the quality connotation of rural landscape, which is conducive to creating a "nostalgic" atmosphere and making villagers have a sense of belonging.

\section{Research contributions and limitations}

\subsection{Research contributions}

(1) From the perspective of research methods, qualitative analysis and quantitative analysis are combined. Firstly, the influence factors are refined through qualitative research. Secondly, through the form of questionnaire survey, the current situation of rural landscape in cold regions is investigated. Thirdly, based on the survey results, the quantitative analysis is carried out, and then the weight proportion of rural landscape influence factors is analyzed, which is conducive to put forward targeted planning guidance suggestions.

(2) From the perspective of research content, this paper clarifies the difficulties in the promotion of rural landscape in cold regions, such as the urgent need to adjust the industrial structure, enhance the regional 
cultural connotation, and make full use of natural resources, so as to make the rural landscape shaping and upgrading more targeted.

\subsection{Research limitations}

This paper is a general investigation and research on the rural landscape in cold regions. The survey found that the industrial homogenization of the rural areas is very serious, and there is a lack of in-depth research on the types of rural landscape cases with different industrial characteristics in cold regions. Therefore, the research on the evaluation and influence factors of rural landscape of different industrial types has become the focus of the next step, and it is worthy of in-depth study.

\section{Acknowledgement}

China National Key R\&D Program during the 13th Five-year Plan Period (No. 2018YFC0704705) ;

Scientific Research Project of East University of Heilongjiang (No. HDFKY190122).

\section{References}

Isabel Martinho. (2001) Historic anthropogenic factors shaping the rural landscape of Portugal's interior alenteio. Arizona: Arizona University Press.

Yuan Qing. (2012) Study on urban and rural landscape planning under the background of urban and rural integration. Beijing: China Construction Industry Press.

Gu Chaolin, Zhang Xiaoming, Zhang Yue, et al. (2019) Rural planning in the new era [M]. Beijing: Science Press.

Robert L, Ryan. (2002) 'Presenting rural character in New England: Local resident perceptions of alternative residential development', Landscape and Urban Planning, 61(1):19-35.

Xia Lei, Cheng Wen, Zhao Tianyu. (2017) 'Research on the evaluation of village settlement landscape in severe cold region based on database', Chinese garden, 11:99-104.

Yuan Qing, Zhang Dongyu. (2019) 'Research on rural landscape in northeast plain based on qualitative analysis', Proceedings of China Urban Planning Annual Meeting, 9:265-273.

Yao long, Liu Yuting. (2015) 'Rural development types in suburban areas based on cluster analysis: a case study of Conghua District, Guangzhou City', Tropical Geography, 35 (3): 427-436.

Robert B, Richard E. (2015) 'Group differences in the enjoy ability of driving through rural landscapes', Landscape and Urban Planning, 47(1):39-45.

Paquette S, Domon G. (2003) 'Changing rurality, changing landscapes: exploring social recomb position using a multi-scale approach', Journal of Rural Studies, 19(9):425-444.

Arriaza M, Canas-Ortega J F, Canas-Madueno J A,etal. (2004) 'Assessing the visual quality of rural landscape', Landscape and Urban Planning, 69(1):115-125.

J.E.Spencer,R.J.Horva, translated by Zhang Luocheng, (1997) 'Formation and evolution of agricultural landscape ', World agriculture, 223:10-13.

Jing Juan, Wang Yanglin, Peng Jian. (2003) 'Landscape diversity and rural industrial structure', Journal of Peking University (NATURAL SCIENCE EDITION), 4:556-564.

Li Wangming, Lou iridium. (2010) 'Analysis of the industrial mechanism of rural landscape: a case study of Anji County, Zhejiang Province', Central China architecture, 28 (01): 117-119. 
Ting Zhou, Erin Kennedy, Eric Koomen, Eveline S. Van Leeuwen. (2020) 'Valuing the effect of land use change on landscape services on the urban-rural fringe', Journal of Environmental Planning and Management, 63(13):116-121.

Du Chunlan, Lin Liman. (2019) 'Rural landscape change based on industrial integration: a case study of Taobao village', Chinese garden, 35 (04): 75-79.

Ren Wei, Han Feng, Yang Chen. (2018) 'Sustainable development model of rural landscape heritage in UK: a case study of Charleston manor', Chinese garden, 34 (11): 15-19.

Wang Ning. (2018) 'Modern interpretation of traditional garden: rural area construction strategy of lanstad in the Netherlands', International urban planning, 33 (03): 118-124.

Yuan Qing, Yu Tingting, Wang Yifei. (2017) 'Research context and Enlightenment of western rural landscape after World War II', Journal of urban planning, (04): 90-96.

Zhao Yongqi, Tian Yinsheng, Tao Wei. (2017) 'Western rural research from 1994 to 2014: from rural landscape to rural society', International urban planning, 32 (01): 74-81.

Jie MENG. (2020) 'Deconstruction and shaping of rural industrial landscape around Harbin under the background of Rural Revitalization', Urban housing, 27 (05): 150-151.

Chang Li. (2020) 'Research on The Planning and Design Strategy of Rural Cultural Landscape Under the Guidance of Rural Tourism', International Journal of Education and Economics ,3(3).

Chen Bing, Yao Zhen, Zhang Hua, Norf Christian. (2020) 'Research on landscape guided Rural Revitalization Planning and design', Chinese garden, 36 (08): 58-62.

Xie Hualin, Liu liming, Xu Wei. (2003) 'Research on aesthetic evaluation of Rural Landscape', Economic geography, (03): 423-426+ 432 . 